\title{
RESEARCH ON THE CAUSES OF THE "UNDERGRADUATE MIGRANT WORKER" PHENOMENON BASED ON THE THEORY OF LABOR MARKET SEGMENTATION
}

\author{
Yuheng Zhang \\ Faculty of Education, Beijing Normal University (China)
}

\begin{abstract}
"Undergraduate migrant worker" is a kind of special phenomenon during the social changes of China. At present, some college graduates with rural household registration cannot find an ideal job under the background of employment difficulties of Chinese college students, then they choose to converge with the migrant workers of their elder generation in the choice of unemployment and employment in order to achieve short-term transition. Therefore, they are called "undergraduate migrant worker" by the researchers and become another special social vulnerable group which following after the "ant clan". What's more, high human capital is possessed by the group of "undergraduate migrant worker", and the phenomenon of "university migrant workers" would be a great waste of labor resources. Therefore, concerns about this group is the key to realizing the rational allocation of human resources, which is also related to the healthy development of social justice and the socialist market economy with Chinese characteristics in the meantime. Based on the survey of "undergraduate migrant worker" in Chengdu, Beijing and Shenzhen, the article studies the factors that affect their employment based on the perspective of the theory of labor market segmentation, focusing on the influence on the selection of this special group under the background of labor market segmentation in China. The materials in this study are collected through in-depth interviews as well as participation and observation, interview materials are processed by means of using Case analysis. The investigation found that:

(1) The dual segmentation of the labor market makes the main labor market like a huge "black hole", which continuously attracts the in burst of college students, therefore it leads to the increase of barriers to entry continuously and affects the choice of employment market for the rural registered college students.

(2) In China, the inter-regional economic development is unbalanced, and regional differences are obvious. The regional division of the labor market has resulted in an imbalance in the allocation of human resources with partial surplus and shortage of talents.

(3) The market segmentation, which is under the control of social stratification order, has weaken the market competition based on the amount of human capital, moreover, the "crowding-out effect" is existed among the rural registered college students due to the exclusive factors such as internal cultural psychology and professional intergenerational inheritance in the main labor market.

Therefore, it is necessary to give full play to the competitive effects of market factors based on human resources, so as to break the ice of institutional isolation and cultural exclusion, accelerate the coordinated development of the region as well as provide equal employment opportunities for the rural registered college students.
\end{abstract}

Keywords: Social change, human resource development, the theory of labor market segmentation, undergraduate migrant workers, cause of formation.

\section{Introduction}

"Undergraduate migrant worker" is a kind of special phenomenon during the social changes of China. At present, some college graduates with rural household registration cannot find an ideal job under the background of employment difficulties of Chinese college students, then they choose to converge with the migrant workers of their elder generation in the choice of unemployment and employment in order to achieve short-term transition. Therefore, they are called "undergraduate migrant worker" by the researchers and become another special social vulnerable group which following after the "ant clan".

Currently, the analysis of the causes of the phenomenon of "undergraduate migrant worker" focuses on the contradiction between college students' ability and the need for ideal employment, that is, their own ability development does not adapt to social needs, and urban-rural differences are not 
conducive to fair employment. Therefore, there is a lack of attention to the impact of the job market itself on college students' career choices, especially the impact of the labor market segmentation. Because if there are no two markets, there will be no situation where college students flow into the secondary labor market and become "undergraduate migrant worker". The phenomenon of "undergraduate migrant worker" is an awkward situation that they face in the process of entering the job market. If it is said that becoming an "undergraduate migrant worker" is the result of a dual labor market, what kind of market mechanism is about their choice? This requires the use of labor market segmentation theory to explore the causes of this phenomenon.

\section{Theoretical perspective and research methods}

\subsection{Segmented labor markets theory}

Segmented Labor Markets Theory (SLM), which originated in the 1960s and 1970s, is a theoretical system composed of a series of theories, including dual labor market segmentation theory, job competition theory, and rank or class division (Jin, L. Z, 2002).

As far as China is concerned, after more than 30 years of reform and opening and economic development, Segmentation of labor market have become a significant feature of China's labor market, which is dynamic, local, and spatial. [11] Among the factors that lead to the division of the labor market, China is different from the West. China has a typical characteristic of institutional division, which is mainly affected by institutions (such as the household registration system, administrative monopoly regulation system, and local protectionist system, etc.) ( $\mathrm{Wu}, \mathrm{K} . \mathrm{M}, 2012)$. In the form of segmentation, it has the characteristics of multiple segmentation. For example, a scholar divided the segmentation of the Chinese labor market into urban and rural divisions (geographic region divisions) and institutional divisions (including Labor market "and" out-of-system labor market ") and industry segmentation (Su,Y.Z, 2002). At this point, a multi-dimensional labor market segmentation pattern formed by the intersection of primary and secondary labor markets, urban and rural labor markets, departments, and occupational labor markets has officially taken shape in China (Li, J. H, \& Zhang, M. L, 2012).

\subsection{Research methods}

This article collects materials through in-depth interviews and participatory observation methods. From July to August 2019, the author visited a number of industrial zones in Chengdu and conducted an employment survey of some migrant workers. The target of this survey was a group of young people between the ages of 20 and 25 who had rural household registration or were from rural areas, had received college education or above, and had mixed occupations with ordinary migrant workers. Their characteristics are in line with the academic definition of " Undergraduate Migrant Worker ". The focus of the survey was on their past education experience and job search process. A total of 45 college student migrant workers were interviewed. The interview time for each subject was about 2 hours, which provided valuable first-hand materials for the research.

It is worth noting that although case study faces the shortcomings of small sample numbers and unconvincing. However, for the exploration of social issues, especially the study of complex social people, case study shows the individual's interpretation of social expectations and the individual's adaptation to structural forces such as social history through individual perspective. Finally, it outlines the general development context, survival trajectory, and thinking mode of the group, which hides behind the individual.

\section{The connection between labor market segmentation and the phenomenon of "Undergraduate Migrant Worker"}

\subsection{The dual labor market makes fierce competition in major labor markets}

The Dual Labor Market Theory holds that the labor market is not a whole, but is divided into two sectors with significant differences, namely the main labor market and the secondary labor market. According to relevant research by Chinese scholars, hold the view that occupations in the main labor market include state agencies, party and mass organizations, business leaders, professional and technical personnel, and clerks. And occupations in the secondary labor market include production and transportation workers and service workers, commercial workers, agricultural workers and so on (Gu, C. B, 2004). Compared with the secondary labor market, the main labor market has the salient features of high wage income, perfect social security system, comfortable working conditions, high level of satisfaction, many opportunities for personal promotion, stable work and so on. In this context, based on the difference between the primary and secondary labor markets, workers must give priority to the main labor market, but the contradiction between supply and demand in the market determines make that 
the main labor market cannot be opened to everyone as a limited resource. Under the decision of market mechanism, the amount of human capital has become a fundamental factor in whether to enter the main labor market. For the country, improving the comprehensive quality of the entire nation, accelerating the process of higher education popularization, and continuously satisfying people's growing desire to receive higher education have been continuously implemented in recent years. However, the number of college students' supply is significantly higher than the demand in China's main labor market, which has directly led to rising barriers to entry into the main labor market. The level of education and professional category are important reasons that affect graduates' career acquisition. Due to rational thinking and mental accounting, many families will choose continuous education investment so that children can win the competition in the main sector, which leads the phenomenon of " the Post-graduate Craze " and " Certificate Craze".

The phenomenon of "Undergraduate Migrant Worker" arises from this background. If college students who graduate from ordinary universities fail, they will inevitably flow into the secondary labor market and even engage in the work of migrant workers, becoming "Undergraduate Migrant Worker".

"When I graduated from junior high school, I wanted to go to technical secondary school to learn technology, but my family was very opposed to it, saying that going to college is the right choice. I didn't get good grades at first, and I don't think I can get into a good university in the future. In the end, I entered a very poor university. When I chose a major, I learned management. I hope that I can join the company and become a leader after graduation. However, it is very difficult for management students who graduated from ordinary schools to find a job corresponding to their major."(LQF, male, born in 1996, graduated from XX College, unmarried, supermarket distributor)

This shows that the phenomenon of "Undergraduate Migrant Worker" is not only due to the low level of their own education and limited human capital, but also because of blindly admiring high-paying majors when they choose college majors. Then they have encountered awkward employment when graduating.

It is worth noting that college students are different from ordinary laborers. As a diploma representation of human capital, they perform outstandingly. Therefore, no matter from the psychological level or social expectations, they tend to choose the main labor market. This desire is even more urgent for college students from rural areas, "You must find a good job in the future. The whole family has spent so much attention on you, and never plan to eat in the soil like your parents. From elementary school to university, these words were repeatedly told by them. Now that I'm in college, can you say that I don't want a decent job? If everyone thinks so, how can individuals be so easy!"(CZ, male, born in 1995, graduated from XX College, unmarried, courier)

This means that the segmentation of the labor market caused by the existence of income differences and the human capital that is characterized by diplomas make the competition for university students' employment on the main labor market increasingly fierce. Therefore, in order to find a satisfactory job, some of them will first choose to engage in some "part-time" as a transition,

"Although I studied civil engineering, I will definitely not be a surveyor here all the time. This work is not as good as you think. We do the same work as migrant workers, but I have not found a better job. Poor family, you know ! I can only choose this small place. (SZ, male, born in 1997, graduated from XX College of XX University, unmarried, surveyor)

It can be seen that some of the "Undergraduate Migrant Worker" just choose to become migrant workers temporarily, not equivalent to the existence of "new generation migrant workers" as a stable social group. The main labor market is still attractive to them.

\subsection{The imbalance in the allocation of human resources with partial surplus and shortage of talents caused by labor market segmentation}

Affected by geography, history, population, society, national system and other factors, China's various regions have shown an uneven economic development. From the perspective of regional division, the eastern region has the best development, the central region has the second, and the western region has the worst; In terms of urban division, provincial capital cities and special municipalities are superior to ordinary prefecture-level cities and small county towns. A prominent disadvantage of this imbalance in regional economic development is that the labor market is characterized by obvious regional divisions, and this relative division formed by regional economic differences will directly affect the rational allocation of human resources. Different regions represent different Development opportunities. Generally speaking, developed areas have many jobs, high wages, and bright prospects. Due to the lack supporting mechanisms to attract talents and human resource transformation capabilities, developing areas have limited appeal to college students. 
Especially for rural college students who need to quickly improve the family's economic situation, their employment choices must first consider the return on education investment, development opportunities and future income expectations. Secondly, life pressure! "I think I may get better development opportunities in big cities. after graduating, I didn't return to the small county in my hometown. Instead, I chose to go to Guangzhou. The competition in Guangzhou was too great. I had studied software design and wanted to go to a large company like Tencent, but it was not satisfactory. After the New Year, I am still going to go back to Guangzhou to see if I can find a way out. "(GC, male, born in 1995, graduated from XX College, unmarried, Street vendors)

Thus, the level of economic development and job treatment have become the fundamental driving force that affect their choice of employment area. This flow is also due to the imbalanced regional economic development in China, which is trendy and centralized. As a result, the talent markets in the developed eastern coastal areas and large and medium-sized cities are overcrowded; On the other hand, employment in small counties and vast rural areas is difficult to recruit, even if wages are not bad. Those who have a hard time finding a job in the talent market only have to go to the manpower market to seek work, and the situation of "college students and migrant workers competing on the same stage" has emerged.

\subsection{The exclusivity of the main labor market has a " squeeze-out effect " on rural college students}

The dual segmentation of the labor market is closely connected with the stratification of social classes. In a stratified society, Different social classes try to monopolize the resources that they have in their own circles by establishing a series of qualifications, rules, and systems to restrict other people's access. Although these qualifications are open to all members of the society and can be obtained through individual efforts, they are exclusive in nature, that is, strong group protectionism. For example, the existence of insiders' cultural psychology has affected the job market, which makes college graduates from rural household registration lagging behind college students from urban household registration in the job selection process. This part of the difference is the result of labor market choices deviating from the market mechanism, and it is also the direct cause of the phenomenon of "Undergraduate Migrant Worker".

"After graduating, I have a good friendship in school. Some classmates with good family backgrounds asked me to go to K-sing, travel, visit their home, etc., but because of economic reasons, it is difficult to integrate into their circle. There was a certain distance between them, then I slowly rejected their invitation, naturally the connection was broken. "(YP, male, born in 1997, graduated from XX College, Unmarried, barbecue owner) Culture is an identity that is created by a specific social group. Therefore, people in different circles have different cultural atmospheres, and differences in cultural strata are manifested as a cultural identity, which discriminates children who grow up in the lower cultural environment. In particular, children from rural families must first break through the constraints of the original culture and then integrate into new culture in order to be accepted by a certain social identity group. However, due to the cultural psychology of insiders, it is a long and tortuous process from breaking through cultural barriers to cultural adaptation.

\section{Conclusion}

Based on the survey of the living situation and job-hunting experiences of 45 "Undergraduate Migrant Worker" and the theory of labor market segmentation, the study found that:

(1) The dual segmentation of the labor market makes the main labor market like a huge "black hole", which continuously attracts the in burst of college students, therefore it leads to the increase of barriers to entry continuously and affects the choice of employment market for the rural registered college students. (2) In China, the inter-regional economic development is unbalanced, and regional differences are obvious. The regional division of the labor market has resulted in an imbalance in the allocation of human resources with partial surplus and shortage of talents. (3) The market segmentation, which is under the control of social stratification order, has weaken the market competition based on the amount of human capital, moreover, the "crowding-out effect" is existed among the rural registered college students due to the exclusive factors such as internal cultural psychology and professional intergenerational inheritance in the main labor market.

Therefore, it is necessary to give full play to the competitive effects of market factors based on human resources, so as to break the ice of institutional isolation and cultural exclusion, accelerate the coordinated development of the region as well as provide equal employment opportunities for the rural registered college students. 


\section{References}

Gu, C. B. (2004) Validation of the dual labor market segmentation theory in China. Research on Education Tsinghua University,08,43-49.

Jin, L. Z. (2011) A review of domestic and foreign scholars' theory of Labor Market Segmentation. Productivity Research,01, 206-209.

Li, J. H., \& Zhang, M. L. (2012) Multidimensional labor market segmentation, college student employment mobility and employment space expansion. Northwest Population,06,84-88.

$\mathrm{Su}$, Y. Z. (2010) Research on the sustainability of labor market segmentation. Economic Theory \& Economic Management, 02, 20-26.

$\mathrm{Wu}, \mathrm{K} . \mathrm{M}$. (2012) The Influence of Industry Monopoly on the Employment of College Students. Education Development Research, 17, 43-48. 